\title{
Association between intraocular pressure and loss of visual field in chronic simple glaucoma
}

\author{
R Vogel, R P Crick, R B Newson, M Shipley, H Blackmore, C J Bulpitt
}

Clinical Research

Department, Merck

Sharp \& Dohme

Research Laboratories,

West Point, PA, USA

R Vogel

Department of Ophthalmology, King's College Hospital,

London

R P Crick

Department of Epidemiology, London School of Hygiene and Tropical Medicine, London

R B Newson

M Shipley

SE Thames Regional Computer Centre, London

H Blackmore

Division of Geriatric Medicine, Geriatric Unit Royal Postgraduate Medical School, London C J Bulpitt

Correspondence to: The Glaucoma Secretary, King's College Hospital, Denmark Hill, London SE5 9RS, England.

Accepted for publication 24 July 1989

\begin{abstract}
This paper reports the analyses on data from 747 patients with chronic simple glaucoma (CSG) recorded in the King's College Hospital glaucoma data base between January 1970 and February 1985, having a mean follow-up time of 5.1 years (mode 8 years) with the object of determining the relationship of intraocular pressure (IOP) and visual field loss in CSG. A highly significant negative relationship was found between the presenting visual field coefficient $(F C)$ and the untreated IOP $(r=-0.26$, $p=0.0001$ ) - that is, the higher the IOP on detection, the worse is the visual field. A weak negative correlation was present between the change of FC per year and the treated IOP $(r=-0.06), p=<0.05)$. At treated IOPs $\leq 18$ mmHg visual field loss averaged 0.6 unit per year and for IOPs $>18 \mathrm{mmHg}$ the average loss was 1.2 units per year. The data confirm both the importance of a raised IOP in the causation of chronic glaucomatous visual field loss and the importance of reducing the IOP in patients with chronic simple glaucoma.
\end{abstract}

The hypothesis that an elevated intraocular pressure (IOP) is a factor in chronic glaucomatous optic atrophy and that control of the IOP will exert a favourable influence on its progress is widely accepted. The evidence for this is mainly inferential and anecdotal, but it is compelling to the degree that clinicians feel that it would be unethical not to attempt this form of treatment. However, many ophthalmologists believe that, in spite of the reduction of IOP to normal levels, the deterioration in visual fields of patients with chronic simple glaucoma (CSG) continues and is little affected by treatment.

Our objectives in making this analysis were:

(1) To determine if a relationship could be demonstrated between the level of untreated IOP and the state of the visual field at presentation in order to answer the question: Are higher untreated IOPs in chronic simple glaucoma associated with more visual field loss?

(2) To determine if a relationship could be demonstrated between the rate of visual field deterioration and the level of the treated IOP, or the extent to which IOP is lowered and the rate of visual field deterioration, in order to answer the question: Is it worth treating chronic simple glaucoma by reducing the IOP?

\section{Patients and methods}

The King's College Hospital glaucoma database was initiated in 1969 with the object of improving patient care and of prospectively exploring the relationship of IOP and other factors to the progress of visual field loss in chronic simple glaucoma and ocular hypertension. ${ }^{1}$ This analysis concerns data on 747 patients unselected other than by the requirement that they have CSG entered into the database between January 1970 and February 1985 and followed up for between 1.02 and 12.78 years (mean $5 \cdot 1 \mathrm{yr}$, mode 8 years). Their median age was 70.25 years, with a range of 18-94 years. Visual field data were provided by the Friedmann Visual Field Analyser and were entered by the 'field cross' method. This involves dividing the $0-30^{\circ}$ field into quadrants. Each quadrant is further divided into three zones which are $0-10^{\circ}, 10^{\circ}-20^{\circ}$, and $20^{\circ}-30^{\circ}$ from the fixation point containing 2,4 , and 3 test loci respectively. The resulting mean threshold sensitivity at all the loci tested was expressed as a visual field coefficient (FC), ${ }^{2}$ for which at age 60 or older a maximum score was taken as 50 FC units (each $\mathrm{FC}$ unit $=(4 \mathrm{~dB}+1) \times 10) .50 \mathrm{FC}$ units is equivalent to an average threshold of $1.6 \mathrm{log}$ units on the Friedmann instrument.

The annual field loss for each patient was calculated by regressing the field coefficient at each follow-up visit against the time since entry into the study.

For analyses using the annual field loss the following exclusions were applied: (1) patients with less than two dated follow-up visual field records; (2) patients with less than one year between first and last follow-up visual fields; (3) eyes showing an annual field loss of $>10 \mathrm{FC}$ or a gain of $>13$ FC units. (The distribution of the annual changes was examined to detect gross outliers. These outliers, as defined above, were omitted in accordance with standard practice with large data sets such as this. Outlying values of this type have an undue and possibly misleading influence on the statistical results.)

Changes in FC were expressed as the mean of the slopes of the individual patients. The Pearson correlation coefficient was used for all calculations except for that on the relationship between mean follow-up IOP and FC slope, for which the Kendall correlation was used. The Kendall correlation coefficient is more reliable than the Pearson when many outlying data points exist, as proved to be the case. 
TABLE I Mean untreated IOP and mean follow-up IOP: $C S G$ worse eye

\begin{tabular}{llll}
\hline$I O P(m m H g)$ & $n$ & Mean & $S D$ \\
\hline Untreated IOP & $595 \star$ & $29 \cdot 3$ & $10 \cdot 4$ \\
Follow-up IOP & $566 \dagger$ & 18.9 & $4 \cdot 1$ \\
\hline
\end{tabular}

*The untreated IOP was not available for 152 patients. †A further 29 patients were excluded because they did not meet the follow-up criteria with regard to field coefficient measurements.

A worse eye analysis has been used, and this was defined by the presenting field coefficient. The measurements and disease code for that eye have then been used in the subsequent analyses. In the case of equality the right eye was used. Patients with no presenting FC for either eye were excluded, leaving 747 patients who could be included in the worse eye follow-up analysis.

\section{Results}

The first analysis undertaken was the relationship between untreated IOP and the visual field coefficient (FC) at presentation.

The mean untreated IOP for 595 patients on whom this information was recorded was $29 \cdot 3$ $\mathrm{mmHg}$ and the mean follow-up IOP $18.9 \mathrm{mmHg}$

TABLE II Mean initial and final field coefficients - CSG worse eyes

\begin{tabular}{llll}
\hline $\begin{array}{l}\text { Visual field } \\
\text { coefficients }\end{array}$ & $n$ & Mean & $S D$ \\
\hline Initial FC & 747 & $24 \cdot 9$ & $15 \cdot 6$ \\
Final FC & 566 & $21 \cdot 2$ & $15 \cdot 7$ \\
\hline
\end{tabular}

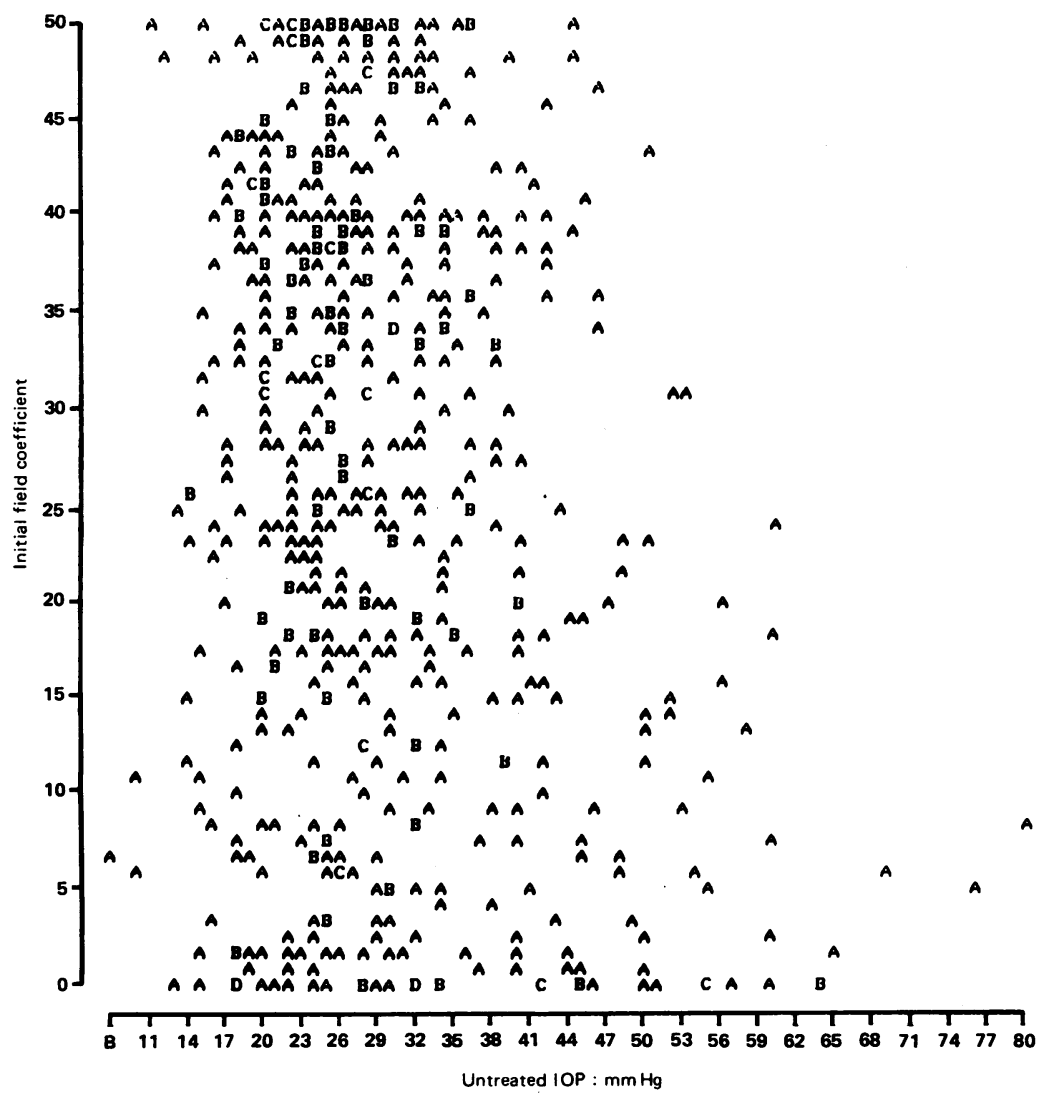

Figure 1: Scatter plot of untreated IOP and initial field coefficient - CSG worse eyes. More than one observation may fall on any point. Thus $\mathrm{A}=1$ observation, $\mathrm{B}=2$ observations, etc
(Table I). In spite of a manual search of original hospital notes the untreated IOP was not available for 152 patients. These patients were already on treatment when entered in the database, and the original Goldmann applanation reading was not known with certainty, so they were excluded. The majority of patients $(66 \%)$ had been on treatment for less than one year prior to being entered into the study population. Figure $l$ is a scatter plot of presenting IOP and initial field coefficient. The Pearson correlation coefficient between presenting IOP and initial FC was calculated and showed a highly significant negative relationship $(\mathrm{r}=-0.26, \mathrm{p}=0.0001)$, demonstrating that at presentation the higher the IOP the worse the visual field. The mean initial and final FCs were calculated, and these are shown in Table 2 . In order to relate final mean FC to initial mean FC and untreated presenting IOP, these were plotted in Figure 2. Patients whose presenting FC was zero were excluded from this figure. The relationship between a high presenting IOP and a poor visual field both initially and at the end of follow-up is demonstrated.

The mean follow-up IOPs were divided into six categories: $\leqslant 14 \mathrm{mmHg},>14$ but $\leqslant 16 \mathrm{mmHg}$, $>16$ but $\leqslant 18,>18$ but $\leqslant 20,>20$ but $\leqslant 22$, and $>22 \mathrm{mmHg}$. The mean annual field loss within these six categories for worse eyes with CSG are shown in Figure 3. The higher mean follow-up IOPs showed greater rates of annual visual field loss, supporting the view that treatment to lower IOP is beneficial in retarding visual field deterioration in CSG. The mean follow-up IOP and the slope of the FC also showed a weak but significant negative relationship (Kendall correlation $\mathrm{r}=-0.06, \mathrm{p}<0.05$ ), thus confirming the above finding.

The doubling in rate of annual field loss between the group with $14 \leqslant 16 \mathrm{mmHg}$ and those with $>22 \mathrm{mmHg}$ has considerable potential clinical importance. The high rate of visual field loss seen in the 22 patients with a mean follow-up IOP of $\leqslant 14 \mathrm{mmHg}$ in their worse eye was due to the fact that this category contained many eyes with complicated surgical histories following years of failed treatment. Several eyes had complications such as progressive cataracts, central vein occlusion, bound down pupils, persistent choroidal detachment, etc.

It was also noted that the lower the initial FC value the greater the difference between untreated and mean follow-up IOP (Pearson correlation coefficient, $r=-0.09, p=0 \cdot 04)$. This might imply that those with more damaged fields were treated more vigorously, which is an expected clinical reaction. Those with low initial FCs (who had higher presenting IOPs) necessarily required a greater fall in IOP to bring the IOPs down to acceptable levels.

\section{Discussion}

Leydhecker ${ }^{3}$ summarised the evidence for the role of an elevated IOP in the genesis of atrophy and excavation of the optic disc. This relationship has been questioned intermittently from the middle of the 19th century. Conversely the presence of an appreciably raised IOP without 
Final Field Coefficient Initial Field Coefficient

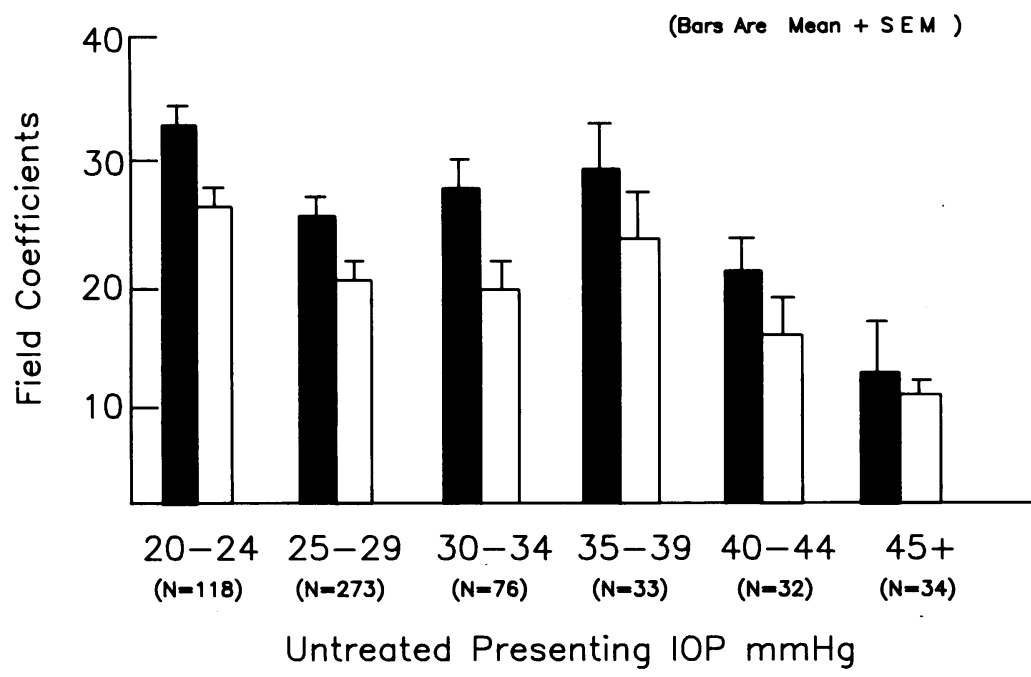

Figure 2: Mean initial and mean final field coefficient versus untreated presenting IOP - CSG worse eyes. (This considers only these 566 eyes with both initial and final field coefficients recorded.)

evidence of optic disc impairment over a considerable period of time has also been recognised.

It is generally accepted that the optic nerve damage in CSG may depend on several factors, including a raised IOP,${ }^{+8}$ heredity, ${ }^{910}$ myopia, ${ }^{11}{ }^{12}$ race, ${ }^{1314} \mathrm{sex},{ }^{115}$ diabetes, ${ }^{1617}$ vascular insufficiency and anaemia, ${ }^{18}{ }^{19}$ and other risk factors yet to be discovered.

The importance of IOP as a factor continues to be a matter of controversy. Leydhecker has made a strong case both for the influence of raised IOP in the causation of chronic glaucomatous optic atrophy and for the beneficial effect of the reduction of IOP on the retardation or arrest of optic nerve damage and therefore of visual field deterioration, reducing the IOP to really low levels if necessary.

Niesel and Flammer ${ }^{20}$ showed in CSG that a significant correlation exists between the standard deviation of the variation of IOP annually and the development of field defect, but they did not find that the relationship between the mean level of pressure itself and field loss reached statistical significance. Their findings were based

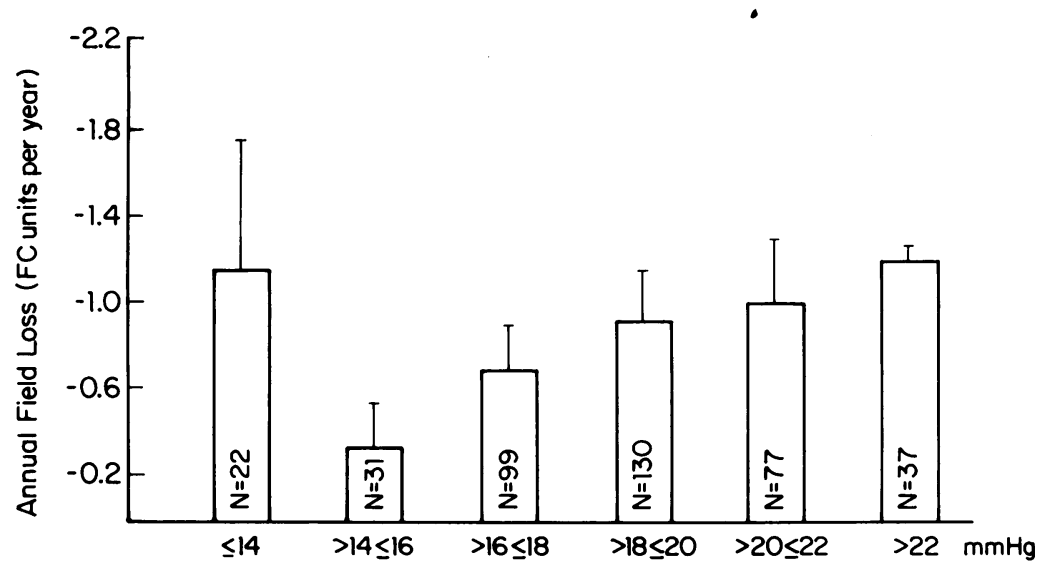

Mean Follow-up IOP (and Standard Error) Worse Eye

Figure 3: Rate of deterioration of visual field coefficient $(F C)$ with standard error bars, against the level of mean follow-up IOP - CSG worse eye. on a group of 33 patients with CSG followed for 11 years.

$\mathrm{Krakau}^{21}$ considers 'that the concept of pressure as the generally valid cause of damage in chronic glaucoma is a hypothesis and not an established fact' but agrees 'that very high pressures are deleterious beyond doubt'. Sponsel et $a l^{22}$ have also questioned the importance of the role of intraocular pressure in the aetiology of the optic atrophy of chronic simple glaucoma. Bengtsson ${ }^{23}$ has highlighted the problem of low tension glaucoma (LTG) in his patients and regards it as being quite frequent. Most ophthalmologists, however, have found that very careful investigation of cases of suspected LTG results in only a small minority of patients being so classified. Bengtsson ${ }^{24}$ also considers that the 'optic neuropathy of glaucoma is due to small vessel disease and not to a low perfusion pressure' and that 'the increase of IOP is an effect rather than a cause of glaucoma'. Treatment by lowering IOP, he claims, is based on obsolete ideas and has never been shown to be justified by any positive effect. As they are presented these views would appear to be lacking good supporting evidence, though the concept of a combination of raised IOP, a varying degree of ischaemic neuropathy, mechanical vulnerability of wide optic cups to pressure, weakness of connective tissue supporting the optic nerve head (for example, as in myopia), and possibly a weakness or abiotrophic tendency of the neural tissue itself as variable components of a 'primary open angle glaucomatous complex', is compatible with clinical observation and would be a useful unifying hypothesis for CSG, ocular hypertension, and low tension glaucoma. ${ }^{25}$

The results of this analysis show in this unselected population a very clear relationship between the untreated IOP and the extent of visual field loss at presentation. This in itself is support for the need to control IOP in patients with glaucoma. The clearest picture of this relationship will exist only at this point, since subsequent reduction in the IOP by therapy should make it increasingly difficult to demonstrate the negative relationship in the sampled population as a whole, though categorical analysis (Fig 3) may still show the same relationship at higher follow-up IOPs. This is indeed what we found.

It may also be expected that any benefit from lowering IOP would be revealed by a higher rate of visual field deterioration prior to presentation compared with that which occurred during the period of treatment. Inevitably we have no data on the annual change in FC prior to detection, and only a randomised trial involving a large group of CSG patients as untreated controls would provide evidence of the effect of IOP reduction. But in view of the existing clinical evidence for efficacy of treatment this may be ethically unacceptable.

Our data suggest (Fig 2) that a true IOP/field loss relationship may be more evident at pressures in excess of $39 \mathrm{mmHg}$, suggesting the possible existence of subgroups within CSG. IOP may not be the dominant influence in the pathogenesis of visual field loss in glaucoma until pressures in excess of $39 \mathrm{mmHg}$ occur. It can be 
hypothesised that the patients with only moderately raised IOPs, that is, $20-35 \mathrm{mmHg}$, have a greater vascular or other element to their glaucomatous field loss than those with a much higher IOP. ${ }^{25}{ }^{26}$ Although we recognise that the correlations between the increasing field loss and IOP are weak and that the statistical significance of the correlation relies heavily on the large sample size, the doubling of the annual rate of loss of field at a treated IOP over $22 \mathrm{mmHg}$ compared with a treated IOP of $>14 \leqslant 16 \mathrm{mmHg}$ has considerable clinical importance.

The apparently divergent views of Leydhecker, Krakau, Bengtsson, Greve, and Sponsel, previously mentioned, all appear to be endorsed in part by the findings of this analysis as representing different aspects of a complex problem. Further analysis is in progress to determine the influence of amplitude of variation of IOP and peak pressures on visual field loss in this series of patients, especially in view of Niesel and Flammer's ${ }^{18}$ observations.

\section{CONCLUSIONS}

We have shown from this analysis, firstly, that the higher the pretreatment IOP the worse is the visual field. Secondly, a negative relationship between IOP and visual field loss is present but is understandably less pronounced once treatment has been instituted. There was a tendency for patients with higher mean follow-up IOPs to lose field faster than those with a lower follow-up IOP. The relationship between treated IOP and continuing field loss does indeed exist but in this analysis was smaller than has hitherto been widely assumed. One reason for the weak relationship found was the poor visual field outcome in the small number $(n=22)$ of patients with a treated IOP of $\leqslant 14 \mathrm{mmHg}$. Many of those patients had complicating factors unrepresentative of the rest of the population. Treatment to reduce the intraocular pressure is therefore important to prevent or reduce the loss of visual field in chronic simple glaucoma.

In practice it would be reasonable in an individual case to reduce the IOP progressively until deterioration of the visual field is arrested. If this cannot be achieved, factors other than IOP may be preponderant. Methods of treating the other factors may be revealed by further research, but in the present state of our knowledge reduction of the IOP is still undoubtedly the ophthalmologist's primary duty when managing chronic glaucoma.
The maintenance of the database involves extensive team work by all the members of the Department of Ophthalmology at King's College Hospital, and we are particularly indebted to Mr Roger Coakes, Dr Patricia Reynolds, Mrs Jean Curtis, and Mrs Eileen Cobb.

We thank the Joint Research Committee of King's College Hospital, Merck Sharp and Dohme, and the Internationa Glaucoma Association for financial support. The help of Mr Colin Clements for illustrations is also appreciated.

1 Crick RP. Prevention of blindness from glaucoma using the King's College Hospital computerized problem orientated King's College Hospital computerized problem or
medical record. Brf Ophthalmol 1975; 59: 236-48.

2 Crick RP. Computerized clinical data base for glaucoma - ten years experience. Res Clin Forums 1980; 2: 29-39.

3 Leydhecker W. Is glaucoma therapy useless? In: Krieglstein GK, Leydhecker W, eds. Glaucoma update II. Berlin: Springer, 1983: 95-102

4 Armaly MF. Ocular pressure and visual fields - a ten year follow-up study. Arch Ophthalmol 1969; 81: 25-40.

5 David R, Livingston DG, Luntz MH. Ocular hypertension - a long term follow-up of treated and untreated patients. $\mathrm{Br} \mathcal{F}$ Ophthalmol 1977; 61: 668-74.

6 Leydhecker W. Die Zuverlassigkeit der Diagnose des Glaucoma simplex in Fruhstadium. Doc Ophthalmol 1966, 20: $214-29$.

7 Daubs JG, Crick RP. Epidemiological analysis of King's College Hospital glaucoma data. Res Clin Forums 1980; 2: 41-62.

8 Wilson R, Walker AM, Dueker DK, Crick RP. Risk factors for progressive glaucomatous visual field loss: a computer for progressive glaucomatous visual field loss: a com
based analysis. Arch Ophthalmol 1982; 100: 737-41.

9 Kellerman L, Posner A. The value of heredity in the detection and study of glaucoma. Am $\mathcal{F}$ Ophthalmol $1955 ; 40: 681-5$.

10 Miller SJH, Paterson GD. Studies on glaucoma relatives. $\mathrm{Br}$ F Ophthalmol 1962; 46: 513-22.

11 Moller HV. Excessive myopia and glaucoma. Acta Ophthalmol (KGh) 1948; 26: 185-93.

12 Daubs JG, Crick RP. The effect of refractive error on the risk of ocular hypertension and primary open angle glaucoma. Trans Ophthalmol Soc UK 1981; 101: 121-6.

13 Wilensky JT, Gandhi N, Pan T. Racial factors in open angle glaucoma. Ann Ophthalmol 1979; 10: 1398-402.

14 Wallace J, Lovell HG. Glaucoma and intraocular pressure in Jamaica. Am $\mathcal{f}$ Ophthalmol 1969; 67: 93-100.

15 Kahn HA, Milton RC. Revised Framingham eye study, prevalence of glaucoma and diabetic retinopathy. $A m \mathcal{F}$ Epidemiol 1980;111: 769-76.

16 Armstrong JR, Daily RK, Dobson HL, Girard LJ. The incidence of glaucoma in diabetes mellitus. Am $\mathcal{f}$ Ophthalmol 1960; 50: 55-63.

17 Davies EWG. Closed angle glaucoma in diabetic patients. Res Clin Forums 1980; 2: 85-8.

18 Drance SM. Some factors involved in the production of low tension glaucoma. Brf Ophthalmol 1972; 56: 229-42.

19 Morgan RW, Drance SM. Chronic open angle glaucoma and ocular hypertension - an epidemiological study. $\mathrm{Br} \mathcal{F}$ Ophthalmol 1975; 59: 211-5.

20 Niesel P, Flammer J. Correlations between IOP, visual field and visual acuity based on 11 years observations of treated chronic glaucoma. Int Ophthalmol 1980; 3: 31-4.

21 Krakau CET. Discussion of paper by Leydhecker W. Is glaucoma therapy useless? In: Krieglstein GK, Leydhecker W, eds. Glaucoma update II Berlin: Springer, 1983:100-1.

22 Sponsel WE, Dallas NL, Burbridge L. Visual field survival: the response to timolol therapy in open angle glaucoma. $B r \mathcal{F}$ Ophthalmol 1983; 67: 220-7.

23 Bengtsson B. Discussion of paper by Leydhecker W. Is glaucoma therapy useless? In: Krieglstein GK, Leydhecker W, eds. Glaucoma update II. Berlin: Springer, 1983: 101.

24 Bangtsson $B$. Aspects of the epidemiology of chronic glaucoma. Acta Ophthalmol (KGh) 1981; 146 (suppl): 1-48.

25 Crick RP, Reynolds PM, Daubs J. Epidemiological aspects of primary open angle glaucoma. Glaucoma 1983; 5: 4-14.

26 Greve E, Geijssen HC. The spectrum of primary open-angle glaucoma. I: Senile sclerotic glaucoma versus high tension glaucoma. Ophthalmic Surg 1987; 18: 207-13. 